\title{
Utilização de influenciadores digitais para a mobilização de seguidores em favor de causas sociais
}

\author{
Carlos Oliveira $^{1}$, Ana Cristina B Garcia ${ }^{1}$, Adriana S Vivacqua ${ }^{2}$ \\ ${ }^{1}$ Departamento de Sistemas de Informação - Universidade Federal do Estado do Rio de Janeiro \\ ${ }^{2}$ Departamento de Ciência da Computação - Universidade Federal do Rio de Janeiro \\ \{carlos.roberto, cristina.bicharra\}@uniriotec.br, avivacqua@dcc.ufrj.br
}

\section{Resumo}

Durante décadas, pessoas de todo o mundo, inclusive no Brasil, pressionaram o governo para participar de suas decisões. O governo digital criou meios para uma ampla interação cidadão-governo, que inclui informar pessoas, ouvir demandas e negociar decisões. Entre as possibilidades de ação do cidadão na internet está a interação com o governo. Um dos principais benefícios relatados da e-participação é que ela melhora a eficácia da formulação de políticas, aumentando as oportunidades de participação dos cidadãos [Tolbert and Mossberger 2006]. Cruickshank et al. [Cruickshank et al. 2010] argumentam que $1 \%$ da participação popular é um resultado bem-sucedido para a democracia. Embora o governo brasileiro tenha criado muitas plataformas de participação, a participação popular é extremamente pequena, quase insignificante, mesmo por apenas visitar os sites para obter informações confiáveis. Então, é um desafio mobilizar as pessoas a exercerem seu direito de participar.

Em uma revisão sistemática da literatura [Oliveira and Garcia 2019], verificamos a existência de 15 diferentes motivos para a baixa participação do cidadão. Dentre esses motivos, o que pretendemos tratar é a não-participação por desconhecimento das possibilidades de participar. Bicking et al. [Bicking et al. 2011] argumentam que a falta de estratégia para divulgar projetos de participação eletrônica nas redes sociais leva a uma baixa audiência nas plataformas desses projetos. Dos estudos de mídia social vem uma possibilidade para solucionar o problema do desconhecimento. Como o nome sugere, os influenciadores digitais influenciam as pessoas [Chatterjee 2011]. Então, que tal usar influenciadores digitais para espalhar rapidamente as notícias sobre direitos de cidadania? Não se trata de manipular pessoas a favor ou contra uma ideia, mas de motivar as pessoas a (1) procurar informações, (2) tomar consciência do que está acontecendo no governo, (3) defender seu direito e (4) mostrar os passos para e-participar. Em outras palavras, os influenciadores digitais podem ser um gatilho para despertar as pessoas para se tornarem cidadãos mais ativos. O desafio passa a ser entender o comportamento dos influenciadores digitais e a formação de intenções. Como os influenciadores digitais selecionam suas mensagens para postar? O que faria um influenciador digital postar material relacionado à cidadania? Quais fatores os impedem de publicar material relacionado à cidadania? Essas questões motivaram nossa pesquisa e apresentamos algumas descobertas interessantes neste trabalho.

Através de entrevistas e questionários, observamos que o que influencia a intenção de postar causas sociais está relacionado a cinco tarefas: Buscar a informação, verificar a credibilidade da informação, verificar possíveis ganhos, verificar o perfil dos seguidores (para checar se a postagem pode causar polaridade) e checar a distância 
temática. Pudemos observar que os entrevistados podem ser classificados em dois grupos muito diferentes, aqueles que veem sua participação nas redes sociais como um negócio, que chamaremos de influenciadores do tipo 1, e aqueles que não vêem sua atuação como um negócio, que chamaremos de influenciadores do tipo 2. Isso é importante porque influencia sua percepção sobre as tarefas necessárias para postar uma causa social. Um influenciador do tipo 1 tem seus seguidores como seu principal ativo e tem muito cuidado para não perdê-los. O número de seguidores limitará os possíveis lucros do influenciador. Portanto, o influenciador do tipo 1 procurará aumentar o número de seguidores postando conteúdo considerado de qualidade pelos seus seguidores. Por outro lado, a maneira de não perder seguidores é verificar a adequação das informações postadas, principalmente não polarizando os seguidores. A causa social geralmente tem um fundo político. Assim, a postagem de causa social pode levar o influenciador a assumir uma posição que pode desagradar parte dos seus seguidores. Quando o influenciador permanece dentro do tema de postagem pelo qual é seguido, diminui o risco de perder seguidores. Os influenciadores do tipo 1 também tendem a limitar suas postagens ao tema de postagem pelo qual são seguidos. Portanto, existe uma chance maior desse tipo de influenciador postar informações sobre causas sociais relacionadas ao seu tema de postagem habitual. Assim, para divulgar uma causa social, influenciadores com pequena distância temática devem ser escolhidos para aumentar as chances de postagem.

Em relação ao comportamento, observamos que os influenciadores do tipo 1 podem ter três comportamentos diferentes. Alguns influenciadores do tipo 1 são estritamente orientados por seus interesses. Outros são altruístas para causas sociais. Um terceiro grupo quer manter seu negócio ao mesmo tempo em que posta orientado por suas crenças. Os influenciadores do tipo 2 são sempre guiados por suas crenças. Os influenciadores do tipo 1 seguem um comportamento planejado de postagens. Os influenciadores do tipo 2 podem fazer postagens planejadas, mas muitas delas não são planejadas, são iniciadas a partir de eventos externos. Isso faz com que seja mais fácil para os influenciadores tipo 2 aceitarem solicitações de postagem. Isso não significa que os influenciadores do tipo 1 não aceitarão solicitações de postagem. Porém, as solicitações devem estar relacionadas ao tema de postagem do influenciador para ter maiores chances de ser postada.

\section{References}

Bicking, M., Triantafillou, A., Henderson, F., Koussouris, S., and Wimmer, M. A. (2011). Lessons from monitoring and assessing ec-funded eparticipation projects: citizen engagement and participation impact. In 2011 IST-Africa Conference Proceedings, pages $1-8$. IEEE.

Chatterjee, P. (2011). Drivers of new product recommending and referral behaviour on social network sites. International Journal of Advertising, 30(1):77-101.

Cruickshank, P., Edelmann, N., and Smith, C. (2010). Signing an e-petition as a transition from lurking to participation. na.

Oliveira, C. and Garcia, A. C. (2019). Citizens' electronic participation: a systematic review of their challenges and how to overcome them. International Journal of Web Based Communities, 15(2):123-150.

Tolbert, C. J. and Mossberger, K. (2006). The effects of e-government on trust and confidence in government. Public administration review, 66(3):354-369. 